\title{
Molecular basis of carcinogenesis in diabetic patients (Review)
}

\author{
ARTUR MATYSZEWSKI ${ }^{1-3}$, ANNA M. CZARNECKA ${ }^{1}$, WOJCIECH SOLAREK ${ }^{1,4}$, \\ PIOTR KORZEN $^{1}$, ILAN J. SAFIR ${ }^{5}$, WOJCIECH KUKWA ${ }^{6}$ and CEZARY SZCZYLIK ${ }^{1}$
}

\author{
${ }^{1}$ Department of Oncology, Military Institute of Medicine, Warsaw; Departments of ${ }^{2}$ Internal Medicine, Cardiology and \\ Hypertension and ${ }^{3}$ Nephrology and Dialysis Center, L. Rydygier Voivodeship Hospital, Suwałki; ${ }^{4}$ Postgraduate School of \\ Molecular Medicine, Medical University of Warsaw, Warsaw, Poland; ${ }^{5}$ Department of Urology, Emory University School \\ of Medicine, Atlanta, GA, USA; ${ }^{6}$ Department of Otolaryngology, Medical University of Warsaw, Warsaw, Poland
}

Received October 16, 2014; Accepted December 10, 2014

DOI: $10.3892 / \mathrm{ijo} .2015 .2865$

\begin{abstract}
The most important molecular mechanisms promoting carcinogenesis in patients with diabetes mellitus (DM) include oxidative stress, excessive generation of free radicals and nitrous oxide, damage to cellular membranes and DNA, overproduction of lactate, overabundance of protein glycosylation storage products, overexpression of pathological enzyme isoforms, and leakage
\end{abstract}

Correspondence to: Dr Artur Matyszewski, Department of Oncology, Military Institute of Medicine, Szaserow 128 Street, Warsaw 04-141, Poland

E-mail: artur.matyszewski@gmail.com

Abbreviations: PI3K, phosphoinositide 3-kinase; PTEN, phosphatase and tensin homolog; mTOR, mammalian target of rapamycin; NK, natural killer; NKT cell, natural killer T cell; IR, insulin receptor; MAPK, mitogen-activated protein kinase; $\mathrm{PKB}$, protein kinase B; IGF-I and -II, insulin-like growth factors I and II; IGFBP, insulin-like growth factor-binding protein; PTP1B, protein tyrosine phosphatase 1B; PKC, protein kinase $\mathrm{C}$; SOCS proteins, suppressors of cytokine signaling proteins; PC-1/ENPP1, plasma cell membrane glycoprotein-1; JAK, janus kinase; STAT, signal transducer and activator of transcription; DM, diabetes mellitus; OGTT, oral glucose tolerance test; HbAlc, glycated hemoglobin; HOMA-IR, homeostasis model assessment of insulin resistance; MHC, major histocompatibility complex; IL, interleukin; INF, interferon; TGF- $\beta$, transforming growth factor- $\beta$; IRS, insulin receptor substrate; GRB protein, growth factor receptor-bound protein; SHC, adapter protein; RAS, RAS protein; TSC1/2, hamartin/tuberin; $L K B 1$ gene, liver kinase B1 gene; Rheb, GTP binding protein; rpS6, ribosomal protein S6; ERK and JNK, mitogen-activated kinases; p90RSK, ribosomal protein $\mathrm{S} 6$ kinase subtype; $\mathrm{CAP} / \mathrm{Cbl} / \mathrm{TC} 10$, signaling pathway; CDC42, cell division control protein 42 homolog; Rac, $\mathrm{G}$ protein (Roc family); PDK, threonine kinase; aPKC, activated protein kinase C; AS160, substrate for the kinase Akt; GSK3, glycogen synthase kinase 3; FOXO1, transcription factor involved in gluconeogenesis and glycogenolysis

Key words: carcinogenesis, diabetes, insulin resistance, obesity, metabolic disorders of cytochromes from organelles. Additionally, dysfunctional signal transduction pathways, especially in pathways involving phosphoinositide 3-kinase (PI3K)/phosphatase and tensin homolog (PTEN)/Akt, RAS/Raf/ERK, and mammalian target of rapamycin (mTOR), have been implicated in malignant transformation and progression. Obesity and metabolic disorders, such as DM, may contribute to a dysfunctional immune system with a suppressed immune response by inducing a chronic inflammatory state, abnormal humoral and cellular mediated immunity, and lower counts and activity levels of natural killer (NK) cells and natural killer T cells (NKT cells). Recent advances in molecular biology will allow for better understanding of abnormal cellular pathways, as well as elucidating how metabolic disorders contribute to oncogenesis. Knowledge gained through these studies may lead to more efficacious oncologic therapies.

\section{Contents}

1. Insulin resistance and hyperinsulinemia

2. Abnormal glucose metabolism and colorectal cancer

3. Abnormal glucose metabolism and pancreatic cancer

4. Abnormal glucose metabolism and liver cancer

5. Abnormal glucose metabolism and breast cancer

6. Abnormal glucose metabolism and endometrial cancer

7. Abnormal glucose metabolism and prostate cancer

8. Abnormal glucose metabolism and lung cancer

9. DM, obesity, and the immune system

10. Conclusions

\section{Insulin resistance and hyperinsulinemia}

Insulin is a peptide hormone produced by pancreatic $\beta$ islet cells, it stimulates the transport of glucose, amino acids, and potassium from circulating blood serum into cells. Binding of the insulin molecule to the insulin receptor (IR) on muscle and liver cells stimulates the induction of glycogen synthesis, fatty acid esterification, lipolysis inhibition, protein catabolism, and gluconeogenesis. IRs are present in two isoforms, IR A and B. As a result of glucose and amino acid transport 


\section{Hyperinsulinemia \\ Direct effect}
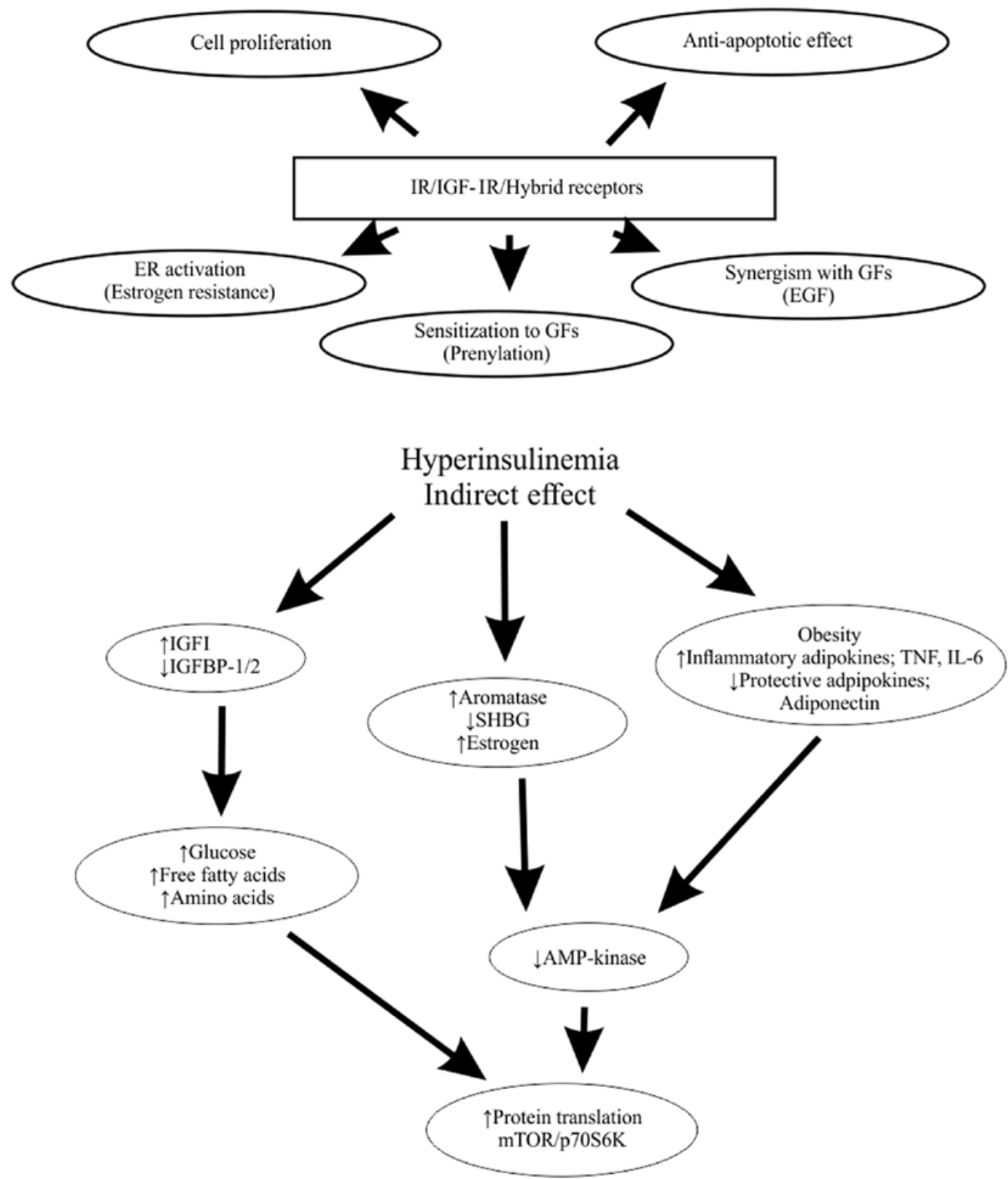

Figure 1. Direct and indirect effects of hyperinsulinemia.

into cells, as well as regulation of intracellular signaling pathways, insulin significantly affects both the cellular transcriptome and proteome (1). Moreover, high serum insulin concentration inhibits autophagocytosis, proteasome activity, and apoptosis (2). Therefore, physiologic insulin concentrations are mainly associated with metabolic effects and higher concentrations stimulate anti-apoptotic and mitogenic effects (3) (Fig. 1).

When insulin binds to its receptor, two pathways become activated: mitogen-activated protein kinase (MAPK) and phosphoinositide 3-kinase (PI3K) pathway (4,5). Activation of MAPK results in transmission of mitogenic signals to the nucleus. Activation of the PI3K pathway leads to protein kinase $\mathrm{B}$ (PKB) activation and conversion to its active form (Akt/PKB). Further activation of the mammalian target of rapamycin (mTOR) pathway enhances protein and fatty acid synthesis and inhibits apoptosis (Fig. 2). Proteins homologous to insulin, insulin-like growth factors I and II (IGF-I and -II), regulate cellular growth and differentiation. This is accomplished by signal transduction pathways through their respective receptors, IGF-IR and -IIR, and also by interactions with insulin-like growth factor-binding proteins (IGFBPs), IGFBP-1 through $6(6,7)$. IGF-I binding to IGF-IR results in increased cellular proliferation and apoptosis inhibition. IGF-II has a similar effect but its function is mainly limited to the fetal period, and plays a major role in the development of major organs. IR and IGF-IR belong to a molecular class of proteins called tyrosine kinase receptors. Intracellular 


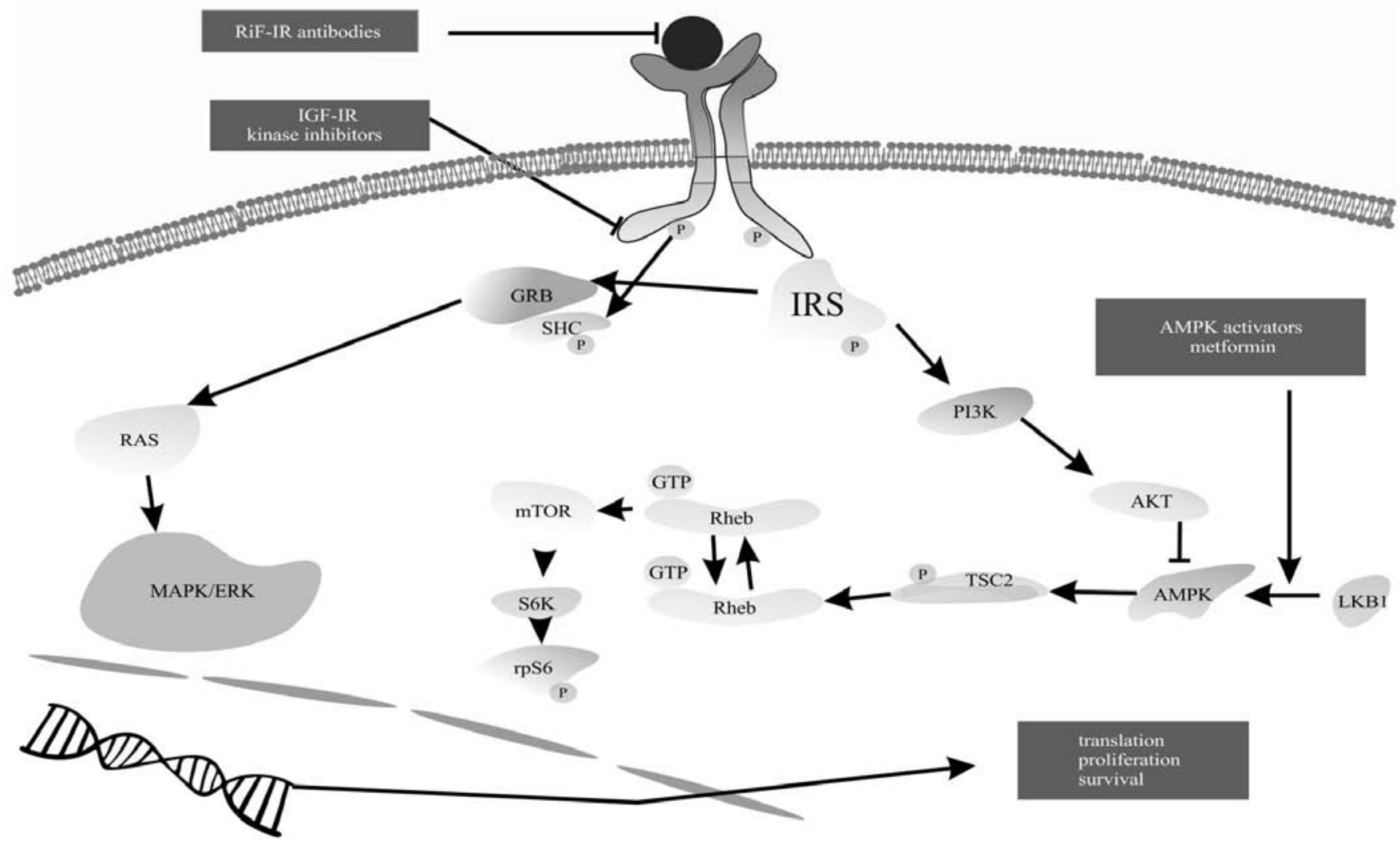

Figure 2. Insulin receptor (IR)- and IGF-dependent intracellular signaling pathways. IRS proteins, insulin receptor substrate proteins; GRB protein, growth factor receptor-bound protein; SHC, adapter protein; RAS, RAS protein; TSC1/2, hamartin/tuberin; LKB1 gene, liver kinase B1 gene; Rheb, GTP binding protein; rpS6, ribosomal protein S6.

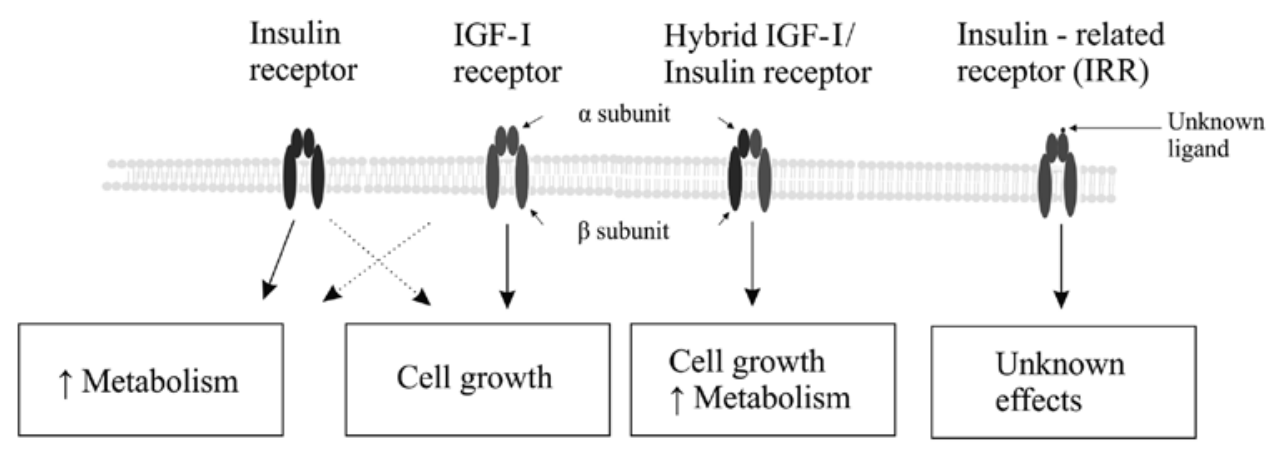

Figure 3. Insulin receptor (IR) family members and their effect on cell metabolism.

pathways activated through IGF-IR by IGF-I are similar to those pathways activated by insulin binding its receptor (8). In high concentrations, insulin activates its own receptor, IR, as well as IGF-IR, stimulating cellular growth and proliferation. A similar cross-receptor activation phenomenon was reported with high IGF-I concentrations (Fig. 3) (9). High post-prandial or exogenously-administrated insulin levels lead to the inhibition of IGFBP-1 synthesis and, therefore, result in increased free IGF-I concentrations (10). Additionally, the activation of IGF-IR and IR appears to be affected by the function of another class of regulatory proteins called tyrosine phosphatases. Specifically, protein tyrosine phosphatase 1B (PTP1B) acts directly on IR, resulting in decreased cellular insulin sensitivity. Furthermore, IR inhibitors appear to increase insulin sensitivity, especially in tumor cells (11).
In vitro and biochemical studies have identified three critical aspects of the insulin signal transduction pathway: IR and IGF-IR binding with their substrates, multiple isoforms of PI3K and Akt (Akt1-3), and multiple isoforms of atypical protein kinase $\mathrm{C}$ (PKC), including PKC $\lambda$ and $\zeta$. Processes associated with the regulation of these aspects impact downstream metabolic steps, cell growth, and cellular viability, and possible carcinogenesis (Fig. 3) (12).

A subset of regulatory proteins affecting cytokine signal pathways also influence the insulin transduction pathway. Examples of these proteins include SOCS1 and 3 proteins, IGF-R binding protein (Grb10), and plasma cell membrane glycoprotein-1 (PC-1/ENPP1) particles (13-18). This subset of proteins reduces the functionality of IR by blocking the interaction of protein kinases, as well as 


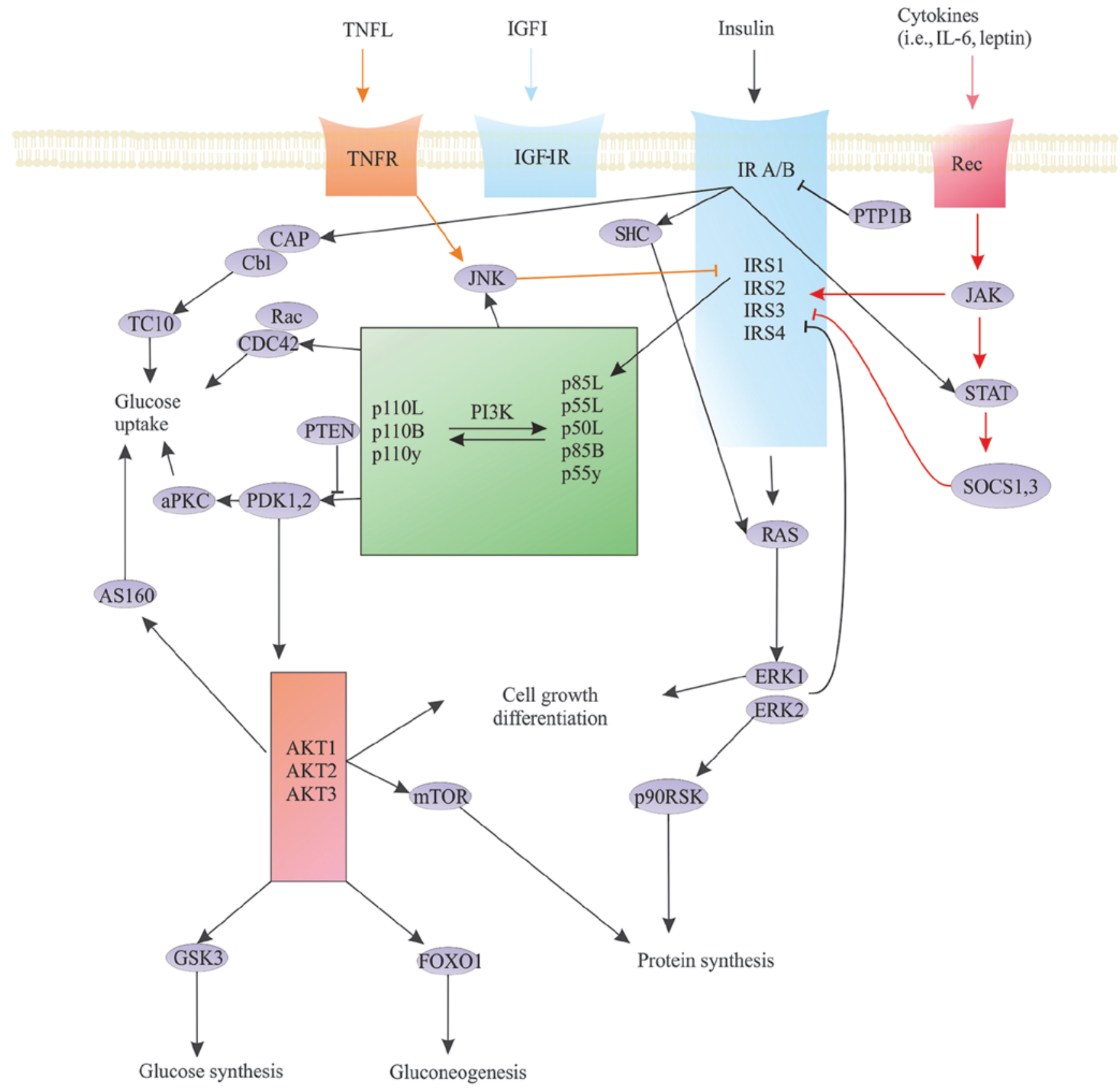

Figure 4. Crucial insulin cell signaling pathway nodes. The concept of critical nodes in the insulin signaling pathways (dark blue arrows) and the very similar network of IGF-IR-dependent signalling (light blue arrows). Cytokines [TNF, interleukin (IL)-6, leptin] interfere with insulin-dependent pathway (orange and red arrows). The three main nodes in the signal transduction pathway of insulin to its receptor (blue box) paired with the insulin receptor substrate (IRS) proteins (light blue box), phosphoinositide 3-kinase (PI3K) (green), and Akt (pink box). JAK, janus kinase; STAT, signal transducer and activator of transcription; SOCS proteins, suppressors of cytokine signaling proteins; PTP1B, protein tyrosine phosphatase 1B; ERK and JNK, mitogen-activated kinases; p90RSK, ribosomal protein S6 kinase subtype; CAP/Cbl/TC10, signaling pathway; CDC42, cell division control protein 42 homolog; Rac, G protein (Roc family); PTEN, phosphatase and tensin homolog - the protein encoded by the tumor suppressor gene PTEN; PDK, threonine kinase; aPKC, activated protein kinase C; AS160, substrate for the kinase Akt; GSK3, glycogen synthase kinase 3; FOXO1, transcription factor involved in gluconeogenesis and glycogenolysis.

modifying receptor-dependent activation. Moreover, SOCS protein concentrations are significantly increased in obesity, promoting insulin resistance. Furthermore, suppressors of cytokine signaling proteins (SOCS proteins) regulate the janus kinase (JAK)/signal transducer and activator of transcription (STAT) pathway; this pathway plays a significant role in the development of many cancer types, especially hematologic malignancies (Fig. 4).

Prior studies demonstrated that tumor cells express increased IR levels. Neoplastic cells may demonstrate $>50 \%$ higher IR expression rates, especially the IR A isoform. This receptor is the fetal variant, activated primarily by IGF-II, and is most frequently observed in breast, lung and thyroid cancers. Moreover, tumor cells also overexpress IGF-I, IGF-IR, and hybrid receptors (19-25). These overexpressed receptors may promote neoplastic growth. IGF-II expression, through the influence on IGF-IR overactivation, may cause growth-promoting conditions as well (26-28). On the other hand, IGF-IIR can bind with IGF-I as well as IGF-II, which sequestrates these signaling molecules from pathologic 
receptors, promoting inhibitory effects (29-31). Dysregulation of molecular mechanisms involving insulin and IGF may be associated with p53 (TP53), the well-studied tumor suppressor protein p53 is known to reduce the expression of both IR and IGF-IR in its normal state and overexpression of these receptors in its mutated state (32).

Several in vitro and in vivo studies, as well as epidemiological analyses, have shown that high levels of insulin and insulin-like growth factors influence cancer development and progression (33-35). Multiple prospective studies demonstrated that the risk of malignancy development and cancer-related deaths is associated with increased serum levels of endogenous insulin, increased levels of IGF-I, and decreased levels of IGFBP-3 (36).

Metabolic pathways activated by PI3K are responsible for a wide range of cellular functions, including fatty acid oxidation inhibition and increased glucose consumption by tumor cells. Blockade of signaling pathways related to PI3K, such as class I inhibitors of PI3K, mTOR, DNA-PK, PLK-1, CK2, ATM and PIM-1, may become a therapeutic strategy for treatment of malignancies (37-39).

\section{Abnormal glucose metabolism and colorectal cancer}

The European Prospective Investigation into Cancer and Nutrition (EPIC) trial demonstrated that hyperinsulinemia, as reflected by increased plasma C-peptide concentration, is associated with a significantly higher risk of developing colorectal cancer, especially rectal cancer (40). The relative risk of cancer in the patient population with the highest quintile of serum $\mathrm{C}$ peptide was $\sim 56 \%$ higher compared to the patient quintile with the lowest $\mathrm{C}$-peptide concentration levels.

Similar conclusions were revealed in the Nurses' Health Study (41). In this study population of surveyed nurses, high C-peptide level was associated with an increased risk of colon cancer by $76 \%$. Moreover, a high ratio of IGF-I to IGFBP-3 increased the risk of cancer by as much as $285 \%$. Interestingly, high IGFBP-1 levels appeared to significantly reduce the risk of neoplasia.

In a prospective cohort study of 14,000 New York females assessing colon cancer risk, it was found that it increases in C-peptide concentration was associated with increased cancer incidence (42). Additionally, it was reported that subjects in the two highest quintiles of IGFBP-1 and -2 serum levels had a decreased colon cancer risk by 52 and $62 \%$, respectively. However, high levels of IGFBP-3 appeared to be associated with an increased cancer risk of up to $246 \%$.

A similar association between colon cancer and elevated C-peptide concentrations was identified in the Physicians' Health Study, a prospective, case-control study (43). One aspect of this study assessed risk factors for malignancy [including age, smoking, alcohol consumption, body mass index (BMI), and physical activity] and cancer diagnosis. Risk factors were highest in subjects in the highest $\mathrm{C}$-peptide concentration quintile.

Other studies assessing patients with colorectal cancer have also demonstrated an association between colon cancer diagnosis with elevated levels of insulin, C peptide and IFG-I as well as reduced IGFBP-1 concentrations $(44,45)$. High levels of $\mathrm{C}$ peptide and low levels of IGFBP-1 were also associated with increased risk of death in patients undergoing surgical treatment for colorectal cancer, including radical colectomy, hemicolectomy as well as high and low rectal amputations (46). This association may be partly explained by a prior diagnosis of diabetes mellitus (DM) and its associated multi-organ system complications, concomitant diagnosis of heart failure, the physiologic stress of surgery, and postoperative surgical complications.

\section{Abnormal glucose metabolism and pancreatic cancer}

Among the various gastrointestinal malignancies, pancreatic cancer is strongly correlated with higher C-peptide concentrations. Michaud et al, in a prospective cohort study of 197 pancreatic cancer patients, determined that the risk of pancreatic cancer diagnosis was increased by $424 \%$ in the highest C-peptide concentration quintile (47). This association was not observed with fasting concentrations of insulin or $\mathrm{C}$ peptide. These observations may suggest that prandial insulin levels may play a role in the development of pancreatic cancer.

\section{Abnormal glucose metabolism and liver cancer}

The Paris Prospective Study assessed 6,200 non-diabetic French men and identified an association between increased insulin levels and death from liver cancer (48). The study evaluated both fasting insulin levels and insulin levels after 120 min following initiation of the standardized oral glucose tolerance test (OGTT). This study found that both elevated fasting insulin levels and elevated insulin levels $120 \mathrm{~min}$ following initiation of the OGTT were significantly associated with an increased risk of dying from liver cancer. The risk of fatal liver cancer was increased by 272 and $341 \%$ in the two highest quintiles for fasting insulin levels and insulin levels $120 \mathrm{~min}$ after initiation of the OGTT, respectively.

\section{Abnormal glucose metabolism and breast cancer}

Recently published studies evaluating the association between derangements in glucose metabolism and subsequent development of breast cancer have demonstrated contradictory findings. In the prospective Nurses' Health Study II, $\sim 75 \%$ of the female subjects were premenopausal (49). This study found that high concentrations of $\mathrm{C}$ peptide were not associated with increased risk of breast cancer. A similar case-control Japanese study, evaluating only postmenopausal women, found that increased C-peptide levels were associated with an increased risk of breast cancer, but only in women with a BMI $>28 \mathrm{~kg} / \mathrm{m}^{2}(50)$. A meta-analysis assessing 20 studies, from 1966 to 2007, demonstrated that DM [primarily type 2 diabetes mellitus (DM2)] increased the risk of breast cancer development by $20 \%$ (51). Further studies will be required to determine how DM specifically promotes oncogenesis in breast cancer, in both the pre- and postmenopausal females. Specific questions that need to be addressed include the role of insulin transduction pathways and insulin's effects on cellular proliferation, anti-apoptosis, and sex hormone metabolism. 


\section{Abnormal glucose metabolism and endometrial cancer}

Results from the aforementioned EPIC study, a prospective, multi-institutional study of the European population, demonstrated that the risk of endometrial cancer increases with higher concentrations of serum C peptide (52). When BMI is taken into account, the increased risk of endometrial cancer is as high as $56 \%$. A case-control study conducted in the United States, Sweden, and Italy, by Lukanova $e t$ al, demonstrated similar findings with regard to the relationship between higher C-peptide levels and increased risk of endometrial cancer $(53,54)$. After adjusting for BMI, the odds ratio assessing the risk of developing endometrial cancer in the highest quintile of serum C-peptide concentration was 4.40 . Lukanova et al also assessed the risk of developing ovarian cancer and found no significant correlation between the risk of ovarian cancer diagnosis and elevated C-peptide concentrations. Furthermore, the authors demonstrated that increased concentrations of IGFBP-1 and -2 were not associated with a reduced risk of endometrial cancer development after adjustment for confounders (53).

\section{Abnormal glucose metabolism and prostate cancer}

Multiple studies have assessed the association between DM and the subsequent development of prostate cancer. A meta-analysis, by Kasper and Giovannucci, showed that the risk of prostate cancer was $\sim 16 \%$ lower in males with DM compared to non-diabetic males (55). One theory to explain this phenomenon is decreased levels of circulating androgens. Decreased androgen levels are associated with insulin resistance states, as in DM2. Reduced levels of endogenous and exogenous insulin may have a protective role in the development of prostate cancer in poorly controlled diabetic males. Conversely, a prospective, multi-institutional study with a multiracial population, conducted in the United States and Canada by Borugian et al, did not identify any association between serum C-peptide concentrations and increased risk of developing prostate cancer (56). Additionally, Roddam et al performed a metanalysis of twelve prospective studies showing little association between prostate cancer risk and IGF-I levels (57).

Ma et $a l$, in a prospective Swedish study, evaluated the impact of many factors associated with impaired glucose metabolism, including BMI, concentrations of C peptide, leptin, glycated hemoglobin (HbA1c), fasting glucose, OGTT test results, and an index of tissue homeostasis model assessment of insulin resistance (HOMA-IR) on the risk of prostate cancer development (58). They observed that the relative risk of death from prostate cancer increased by $56 \%$ in patients who were overweight. Moreover, the increased risk of cancer-related death in obese patients was $>2.6$-fold. Additionally, men with $\mathrm{C}$-peptide concentrations in the highest quartile versus the lowest quartile had a higher risk of prostate cancer mortality (HR 2.38). The relative risk of death from prostate cancer in patients with a BMI $>25 \mathrm{~kg} / \mathrm{m}^{2}$ and C-peptide concentration in the upper quintiles was 4-fold higher than in patients with normal BMI and C-peptide concentrations in the lower quintiles. The study suggested a relationship between impaired glucose metabolism and increased risk of aggressive forms of prostate cancer development; however, these findings did not reach statistical significance. According to Ma et al (57), these results may suggest that in diabetic males, an important factor affecting the initial phase of prostate cancer development is reduced androgen levels whereas in later stages of tumor development, insulin mitogenic effects may play a dominant role; however, further studies are warranted to explore this theory.

\section{Abnormal glucose metabolism and lung cancer}

Lung cancer has the highest malignancy incidence and mortality rates in developed countries. Given its high global prevalence, many molecular studies on lung cancer tumor cell lines and animal models exist. Additionally, multiple studies have assessed possible associations between abnormal glucose metabolism conditions and the subsequent development of lung cancer. Numerous clinical studies demonstrated no statistically significant association between serum abnormalities reflective of abnormal glucose metabolism and subsequent development of lung cancer $(59,60)$. London et al, in a prospective study of Chinese men, found no relationship between high concentrations of IFG-I and increased risk of lung cancer (61). Moreover, they noted a decreased risk of lung cancer with higher IGFBP-3 concentrations. On the other hand, a nested case-control study based on the $\beta$-Carotene and Retinol Efficacy Trial (CARET), an American study assessing lung cancer chemoprevention in smokers and individuals exposed to passive smoking, found that increased IGF-I concentrations were associated with a reduced risk of developing lung cancer, while higher levels of IGFBP-3 were associated with an increased risk of developing lung cancer (62).

\section{DM, obesity, and the immune system}

Diabetic patients have dysfunctional innate and adaptive immune systems, resulting in increased susceptibility to infections and subsequent development of immune system disorders $(1,63,64)$.Immune system dysfunction may ultimately lead to increased risk of cancer development. The cell types most actively involved in the destruction of malignant cells are natural killer (NK) cells and natural killer T cells (NKT cells).

NK cells are a type of peripheral blood lymphocyte and account for $\sim 10-19 \%$ of peripheral lymphocytes. NK cells are responsible for the phenomenon of 'natural cytotoxicity' and are involved in the early stages of non-specific immune surveillance and response to abnormal foreign and host cells. They are likely derived from a common lymphopoietic progenitor cell line and are subjected to selection mechanisms, as evidenced by the observed phenomenon of hybrid resistance. NK cells belong to a group of immune cells called ' $\mathrm{K}$ cells' that are involved in antibody-dependent cytotoxicity. Other $\mathrm{K}$ cells include, macrophages, monocytes, certain $\mathrm{T}$ lymphocytes, neutrophils, eosinophils, and thrombocytes. NK cellular membrane surfaces contain characteristic protein markers, including CD16, 56 and 57. They lack CD3. NK cells are distinguished by their ability to spontaneously kill targeted foreign and abnormal host cells without prior immunization. NK cells identify their targets by evaluating the targeted cell's concentration of surface cell markers. A reduced concentration or complete loss of cell 
surface molecules, such as class I major histocompatibility complex (MHC) proteins, activates the NK cell's cytotoxic mechanism and subsequent destruction of the targeted cell. Reduction or complete lack of class I MHC proteins is characteristic of viruses and cancer cells. The class I MHC status of cells is verified through various receptors, including immunoglobulin-like receptors (KIR, NCR, ILT, LAIR, lectin receptors), and the CD94/NKG2 family of receptors. Potent activators of NK cells are interleukin (IL)- 2 and -4 , interferon (INF)- $\alpha$ and $-\gamma$. NK cell inhibitors include prostaglandin E2 and transforming growth factor- $\beta$ (TGF- $\beta$ ).

Individual differences in NK cell activity levels depend on multiple genetic and environmental factors. Prior studies demonstrated increased NK cellular activity in physically active individuals, especially athletes (1,65-67). Reduced activity was observed in individuals with high-fat diets. Additionally, it was observed that chronic stress and depression result in abnormal NK cell activity $(68,69)$.

NK cells were first described in the 1970s when mechanisms of lymphocyte-specific tumor cell cytotoxicity were being investigated (70-72). Their antitumor mechanisms were confirmed in subsequent animal studies $(73,74)$. Prior studies have shown that high NK cell activity is associated with a lower risk of cancer development (75). Moreover, the activity of these cells in oncologic patients is dependent on the disease phase and progression. NK activity in patients with malignant tumors without distant metastases is generally similar or slightly reduced compared to healthy individuals. On the other hand, NK activity is significantly reduced in patients with metastatic disease (76).

NKT cells are the subject of many studies evaluating the role of the immune system in autoimmune diseases and malignancy (77-80). They are aptly named 'natural killer T cells' due to the cells possessing surface T-cell markers (CD3-TCR complex), surface NK cell markers (CD56, 161 and 94), and marker CD57. Studies suggest that NKT cells mature in the thymus, like B and $\mathrm{T}$ lymphocytes. A particularly large number of NKT cells are located in the liver, accounting for up to $40 \%$ of total cells in the organ. Conversely, NKT cells make up a very small percentage of peripheral blood lymphocytes, accounting for $\sim 1-5 \%$ of all peripheral blood $\mathrm{T}$ cells (81). Despite their low number, NKT cells play an important role in immunoregulation. Due to their cytotoxic abilities, NKT cells are likely involved in the elimination of certain pathogens, including viruses, intracellular bacteria, and protozoa, as well as abnormal host cells, such as tumor cells. The NKT cell receptor has low molecular variability and is able to recognize abnormal surface class I MHC molecules presented by dysfunctional host cells, such as host cells infected by viruses or intracellular bacteria or malignantly-transformed host cells. NKT cells usually lack CD4 and 8 surface markers and, when activated, secrete large concentrations of IL-4 and IFN- $\gamma$ (82-86). NKT cells, similar to $\mathrm{T}$ cell lymphocytes, may also be subject to immune polarization, an observed phenomenon when immune cells differentiate into distinct effector cell types in response to different cytokines.

Prior studies have shown that obesity and prediabetes are associated with a reduction in both NK and NKT cell activity levels (87). Lynch et al evaluated NK cell popula- tions in three different patient groups: obese individuals with metabolic syndrome, obese individuals without metabolic syndrome, and non-overweight individuals without metabolic syndrome (serving as the control group) (88). The mean age and BMI in both obese groups were comparable. They observed that in obese subjects, peripheral blood NK cell and cytotoxic lymphocyte numbers were significantly lower when compared to the control group. Moreover, regardless of age or actual BMI value, obese subjects without metabolic syndrome had significantly higher percentages of NK and cytotoxic lymphocytes than obese subjects with metabolic syndrome (NK cells 11.7 vs. $6.5 \%$, respectively, $\mathrm{p}=0.0001 ; \mathrm{CD} 8$ cells $13.4 \%$ vs. $9.3 \%$, respectively, $\mathrm{p}=0.04)$. Additionally, NK cell activity was also significantly higher in obese individuals without metabolic syndrome versus obese individuals with metabolic syndrome. Further studies are warranted to determine whether metabolic disorders play a causal role in the reduction of NK cell number and function or whether a better functioning immune system protects obese individuals from metabolic disorders and complications.

In some organs, such as the liver as discussed above, the percentage of NKT cells is greater than in peripheral blood. Examination of human peritoneal samples confirmed such findings (89). Analysis revealed up to $15 \%$ of NKT cells in the peritoneum depending on the NKT cell subtypes (10\% iNKT, $15 \%$ with CD1d expression) compared to $\sim 1 \%$ in peripheral blood. Compared to healthy controls with normal BMI, the peritoneal iNKT cell number was significantly lower in morbidly obese subjects $(\mathrm{p}=0.005)$ and in subjects with colorectal cancer $(\mathrm{p}=0.004)(89)$.

Numerous studies suggest that obesity, metabolic disorders, and cancer are accompanied by adverse changes in NK and NKT cell populations, which are manifested primarily by a decrease in cell number and activity. The mechanisms responsible for these adverse immunologic changes are not yet understood.

\section{Conclusions}

The most important molecular mechanisms underlying the development and progression of cancer in patients with DM include oxidative stresses, generation of reactive oxygen species and nitric oxide with subsequent damage to cell membranes and DNA, overproduction of lactate byproducts, and pathological overexpression of certain enzymes. Additionally, derangements in the insulin-receptor signal transduction pathways and an impaired immune system may contribute to oncogenesis. Obesity and metabolic disorders contribute to a chronic inflammatory state, dysfunctional humoral and cellular immune responses, and decreased number and activity levels of NK and NKT cell populations. Additionally, studies have demonstrated an association between abnormal glucose metabolism and increased incidence of multiple malignancies, including colorectal, pancreatic, liver, breast, endometrial and prostate cancers.

\section{Acknowledgements}

This study was supported by the National Science Centre (NCN) (Krakow, Poland) grant no. UMO- 2012/05/D/NZ5/01844. 


\section{References}

1. Piatkiewicz $P$ and Czech A: Glucose metabolism disorders and the risk of cancer. Arch Immunol Ther Exp (Warsz) 59: 215-230, 2011.

2. Bergamini E, Cavallini G, Donati A and Gori Z: The role of autophagy in aging: its essential part in the anti-aging mechanism of caloric restriction. Ann NY Acad Sci 1114: 69-78, 2007.

3. De Meyts P: The structural basis of insulin and insulin-like growth factor-I receptor binding and negative co-operativity, and its relevance to mitogenic versus metabolic signalling. Diabetologia 37 (Suppl 2): S135-S148, 1994.

4. Jensen $M$ and De Meyts P: Molecular mechanisms of differential intracellular signaling from the insulin receptor. Vitam Horm 80: 51-75, 2009.

5. Hermann C, Assmus B, Urbich C, Zeiher AM and Dimmeler S: Insulin-mediated stimulation of protein kinase Akt: A potent survival signaling cascade for endothelial cells. Arterioscler Thromb Vasc Biol 20: 402-409, 2000.

6. Hwa V, Oh Y and Rosenfeld RG: The insulin-like growth factor-binding protein (IGFBP) superfamily. Endocr Rev 20: 761-787, 1999.

7. Holly J and Perks C: The role of insulin-like growth factor binding proteins. Neuroendocrinology 83: 154-160, 2006.

8. Jones JI and Clemmons DR: Insulin-like growth factors and their binding proteins: biological actions. Endocr Rev 16: 3-34, 1995.

9. Werner H, Weinstein D and Bentov I: Similarities and differences between insulin and IGF-I: structures, receptors, and signalling pathways. Arch Physiol Biochem 114: 17-22, 2008.

10. Lee PD, Giudice LC, Conover CA and Powell DR: Insulin-like growth factor binding protein-1: recent findings and new directions. Proc Soc Exp Biol Med 216: 319-357, 1997.

11. Gum RJ, Gaede LL, Koterski SL, et al: Reduction of protein tyrosine phosphatase 1B increases insulin-dependent signaling in ob/ob mice. Diabetes 52: 21-28, 2003.

12. Taniguchi CM, Emanuelli B and Kahn CR: Critical nodes in signalling pathways: insights into insulin action. Nat Rev Mol Cell Biol 7: 85-96, 2006.

13. Ueki K, Kondo T and Kahn CR: Suppressor of cytokine signaling 1 (SOCS-1) and SOCS-3 cause insulin resistance through inhibition of tyrosine phosphorylation of insulin receptor substrate proteins by discrete mechanisms. Mol Cell Biol 24 5434-5446, 2004.

14. Ueki K, Kondo T, Tseng YH and Kahn CR: Central role of suppressors of cytokine signaling proteins in hepatic steatosis, insulin resistance, and the metabolic syndrome in the mouse. Proc Natl Acad Sci USA 101: 10422-10427, 2004.

15. Emanuelli B, Peraldi P, Filloux C, Sawka-Verhelle D, Hilton D and Van Obberghen E: SOCS-3 is an insulin-induced negative regulator of insulin signaling. J Biol Chem 275: 15985-15991, 2000.

16. Emanuelli B, Peraldi P, Filloux C, et al: SOCS-3 inhibits insulin signaling and is up-regulated in response to tumor necrosis factor-alpha in the adipose tissue of obese mice. J Biol Chem 276 : 47944-47949, 2001.

17. Wick KR, Werner ED, Langlais P, et al: Grb10 inhibits insulinstimulated insulin receptor substrate (IRS)-phosphatidylinositol 3-kinase/Akt signaling pathway by disrupting the association of IRS-1/IRS-2 with the insulin receptor. J Biol Chem 278 : 8460-8467, 2003.

18. Dong H, Maddux BA, Altomonte J, et al: Increased hepatic levels of the insulin receptor inhibitor, PC-1/NPP1, induce insulin resistance and glucose intolerance. Diabetes 54 367-372, 2005

19. Kellerer M, von Eye Corleta H, Mühlhöfer A, et al: Insulin- and insulin-like growth-factor-I receptor tyrosine-kinase activities in human renal carcinoma. Int J Cancer 62: 501-507, 1995.

20. Corleta HE, Capp E and Corleta OC: Insulin receptor tyrosine kinase activity in colon carcinoma. Braz J Med Biol Res 29 . 1593-1597, 1996.

21. Werner H and Le Roith D: New concepts in regulation and function of the insulin-like growth factors: implications for understanding normal growth and neoplasia. Cell Mol Life Sci 57: 932-942, 2000.

22. Yi HK, Hwang PH, Yang DH, Kang CW and Lee DY: Expression of the insulin-like growth factors (IGFs) and the IGF-binding proteins (IGFBPs) in human gastric cancer cells. Eur J Cancer 37: 2257-2263, 2001
23. Hudelist G, Wagner T, Rosner M, et al: Intratumoral IGF-I protein expression is selectively upregulated in breast cancer patients with BRCA1/2 mutations. Endocr Relat Cancer 14: 1053-1062, 2007

24. Kim WY, Jin Q, Oh SH, et al: Elevated epithelial insulin-like growth factor expression is a risk factor for lung cancer development. Cancer Res 69: 7439-7448, 2009.

25. Werner $\mathrm{H}$ and Bruchim I: The insulin-like growth factor-I receptor as an oncogene. Arch Physiol Biochem 115: 58-71, 2009.

26. Vella V, Pandini G, Sciacca L, et al: A novel autocrine loop involving IGF-II and the insulin receptor isoform-A stimulates growth of thyroid cancer. J Clin Endocrinol Metab 87: 245-254, 2002.

27. Boulle N, Logié A, Gicquel C, Perin L and Le Bouc Y: Increased levels of insulin-like growth factor II (IGF-II) and IGF-binding protein-2 are associated with malignancy in sporadic adrenocortical tumors. J Clin Endocrinol Metab 83: 1713-1720, 1998.

28. Moorehead RA, Sanchez OH, Baldwin RM and Khokha R: Transgenic overexpression of IGF-II induces spontaneous lung tumors: a model for human lung adenocarcinoma. Oncogene 22: 853-857, 2003

29. Lee JS, Weiss J, Martin JL and Scott CD: Increased expression of the mannose 6-phosphate/insulin-like growth factor-II receptor in breast cancer cells alters tumorigenic properties in vitro and in vivo. Int J Cancer 107: 564-570, 2003.

30. Hebert E: Mannose-6-phosphate/insulin-like growth factor II receptor expression and tumor development. Biosci Rep 26: 7-17, 2006.

31. El-Shewy HM and Luttrell LM: Insulin-like growth factor- $2 /$ mannose- 6 phosphate receptors. Vitam Horm 80: 667-697, 2009

32. Larsson O, Girnita A and Girnita L: Role of insulin-like growth factor 1 receptor signalling in cancer. Br J Cancer 92: 2097-2101, 2005.

33. LeRoith D and Roberts CT Jr: The insulin-like growth factor system and cancer. Cancer Lett 195: 127-137, 2003.

34. Frasca F, Pandini G, Sciacca L, et al: The role of insulin receptors and IGF-I receptors in cancer and other diseases. Arch Physiol Biochem 114: 23-37, 2008.

35. Godsland IF: Insulin resistance and hyperinsulinaemia in the development and progression of cancer. Clin Sci (Lond) 118: 315-332, 2009.

36. Renehan AG, Zwahlen M, Minder C, O'Dwyer ST, Shalet SM and Egger M: Insulin-like growth factor (IGF)-I, IGF binding protein-3, and cancer risk: systematic review and meta-regression analysis. Lancet 363: 1346-1353, 2004.

37. Ihle NT and Powis G: Take your PIK: phosphatidylinositol 3-kinase inhibitors race through the clinic and toward cancer therapy. Mol Cancer Ther 8: 1-9, 2009.

38. Robey RB and Hay N: Is Akt the 'Warburg kinase'?-Akt-energy metabolism interactions and oncogenesis. Semin Cancer Biol 19: 25-31, 2009.

39. Courtney KD, Corcoran RB and Engelman JA: The PI3K pathway as drug target in human cancer. J Clin Oncol 28: 1075-1083, 2010.

40. Jenab M, Riboli E, Cleveland RJ, et al: Serum C-peptide, IGFBP-1 and IGFBP-2 and risk of colon and rectal cancers in the European Prospective Investigation into Cancer and Nutrition. Int J Cancer 121: 368-376, 2007.

41. Wei EK, Ma J, Pollak MN, et al: A prospective study of C-peptide, insulin-like growth factor-I, insulin-like growth factor binding protein-1, and the risk of colorectal cancer in women. Cancer Epidemiol Biomarkers Prev 14: 850-855, 2005.

42. Kaaks R, Toniolo P, Akhmedkhanov A, et al: Serum C-peptide, insulin-like growth factor (IGF)-I, IGF-binding proteins, and colorectal cancer risk in women. J Natl Cancer Inst 92: 1592-1600, 2000.

43. Ma J, Giovannucci E, Pollak M, et al: A prospective study of plasma C-peptide and colorectal cancer risk in men. J Natl Cancer Inst 96: 546-553, 2004.

44. Schoen RE, Tangen CM, Kuller LH, et al: Increased blood glucose and insulin, body size, and incident colorectal cancer. J Natl Cancer Inst 91: 1147-1154, 1999.

45. Le Marchand L, Wang H, Rinaldi S, et al: Associations of plasma C-peptide and IGFBP-1 levels with risk of colorectal adenoma in a multiethnic population. Cancer Epidemiol Biomarkers Prev 19: 1471-1477, 2010.

46. Wolpin BM, Meyerhardt JA, Chan AT, et al: Insulin, the insulin-like growth factor axis, and mortality in patients with nonmetastatic colorectal cancer. J Clin Oncol 27: 176-185, 2009. 
47. Michaud DS, Wolpin B, Giovannucci E, et al: Prediagnostic plasma C-peptide and pancreatic cancer risk in men and women. Cancer Epidemiol Biomarkers Prev 16: 2101-2109, 2007.

48. Balkau B, Kahn HS, Courbon D, Eschwège E, Ducimetière $\mathrm{P}$ Paris Prospective Study: Hyperinsulinemia predicts fatal liver cancer but is inversely associated with fatal cancer at some other sites: the Paris Prospective Study. Diabetes Care 24: 843-849, 2001.

49. Eliassen AH, Tworoger SS, Mantzoros CS, Pollak MN and Hankinson SE: Circulating insulin and c-peptide levels and risk of breast cancer among predominately premenopausal women. Cancer Epidemiol Biomarkers Prev 16: 161-164, 2007.

50. Hirose K, Toyama T, Iwata H, Takezaki T, Hamajima N and Tajima K: Insulin, insulin-like growth factor-I and breast cancer risk in Japanese women. Asian Pac J Cancer Prev 4: 239-246, 2003.

51. Larsson SC, Mantzoros CS and Wolk A: Diabetes mellitus and risk of breast cancer: a meta-analysis. Int J Cancer 121: 856-862, 2007.

52. Cust AE, Allen NE, Rinaldi S, et al: Serum levels of C-peptide, IGFBP-1 and IGFBP-2 and endometrial cancer risk; results from the European prospective investigation into cancer and nutrition. Int J Cancer 120: 2656-2664, 2007.

53. Lukanova A, Lundin E, Micheli A, et al: Risk of ovarian cancer in relation to prediagnostic levels of C-peptide, insulin-like growth factor binding proteins-1 and -2 (USA, Sweden, Italy). Cancer Causes Control 14: 285-292, 2003.

54. Lukanova A, Zeleniuch-Jacquotte A, Lundin E, et al: Prediagnostic levels of C-peptide, IGF-I, IGFBP -1, -2 and -3 and risk of endometrial cancer. Int J Cancer 108: 262-268, 2004.

55. Kasper JS and Giovannucci E: A meta-analysis of diabetes mellitus and the risk of prostate cancer. Cancer Epidemiol Biomarkers Prev 15: 2056-2062, 2006.

56. Borugian MJ, Spinelli JJ, Sun Z, et al: Prediagnostic C-peptide and risk of prostate cancer. Cancer Epidemiol Biomarkers Prev 16: 2164-2165, 2007.

57. Roddam AW, Allen NE, Appleby $\mathrm{P}$, et al: Insulin-like growth factors, their binding proteins, and prostate cancer risk: analysis of individual patient data from 12 prospective studies. Ann Intern Med 149: 461-471, w83-w88, 2008.

58. Ma J, Li H, Giovannucci E, et al: Prediagnostic body-mass index, plasma C-peptide concentration, and prostate cancer-specific mortality in men with prostate cancer: a long-term survival analysis. Lancet Oncol 9: 1039-1047, 2008.

59. Ahn J, Weinstein SJ, Snyder K, Pollak MN, Virtamo J and Albanes D: No association between serum insulin-like growth factor (IGF)-I, IGF-binding protein-3, and lung cancer risk Cancer Epidemiol Biomarkers Prev 15: 2010-2012, 2006.

60. Lukanova A, Toniolo P, Akhmedkhanov A, et al: A prospective study of insulin-like growth factor-I, IGF-binding proteins-1, -2 and -3 and lung cancer risk in women. Int J Cancer 92: 888-892, 2001.

61. London SJ, Yuan JM, Travlos GS, et al: Insulin-like growth factor I, IGF-binding protein 3 , and lung cancer risk in a prospective study of men in China. J Natl Cancer Inst 94 749-754, 2002.

62. Spitz MR, Barnett MJ, Goodman GE, Thornquist MD, Wu $\mathrm{X}$ and Pollak M: Serum insulin-like growth factor (IGF) and IGF-binding protein levels and risk of lung cancer: a case-control study nested in the beta-Carotene and Retinol Efficacy Trial Cohort. Cancer Epidemiol Biomarkers Prev 11: 1413-1418, 2002.

63. Joshi N, Caputo GM, Weitekamp MR and Karchmer AW: Infections in patients with diabetes mellitus. N Engl J Med 341: 1906-1912, 1999

64. Muller LM, Gorter KJ, Hak E, et al: Increased risk of common infections in patients with type 1 and type 2 diabetes mellitus. Clin Infect Dis 41: 281-288, 2005.

65. Takahashi K, Iwase M, Yamashita K, et al: The elevation of natural killer cell activity induced by laughter in a crossover designed study. Int J Mol Med 8: 645-650, 2001.

66. Li Q, Kobayashi M, Inagaki $\mathrm{H}$, et al: A day trip to a forest park increases human natural killer activity and the expression of anti-cancer proteins in male subjects. J Biol Regul Homeost Agents 24: 157-165, 2010.

67. Hayashi T, Tsujii S, Iburi T, et al: Laughter up-regulates the genes related to NK cell activity in diabetes. Biomed Res 28: 281-285, 2007.
68. Maes M, Meltzer HY, Stevens W, Calabrese J and Cosyns P. Natural killer cell activity in major depression: relation to circulating natural killer cells, cellular indices of the immune response, and depressive phenomenology. Prog Neuropsychopharmacol Biol Psychiatry 18: 717-730, 1994.

69. Reiche EM, Nunes SO and Morimoto HK: Stress, depression, the immune system, and cancer. Lancet Oncol 5: 617-625, 2004.

70. Kiessling R, Klein E, Pross H and Wigzell H: 'Natural' killer cells in the mouse. II. Cytotoxic cells with specificity for mouse Moloney leukemia cells. Characteristics of the killer cell. Eur J Immunol 5: 117-121, 1975.

71. Kiessling R, Petranyi G, Kärre K, Jondal M, Tracey D and Wigzell H: Killer cells: a functional comparison between natural, immune T-cell and antibody-dependent in vitro systems. J Exp Med 143: 772-780, 1976.

72. Roder JC, Kiessling R, Biberfeld P and Andersson B: Target-effector interaction in the natural killer (NK) cell system. II. The isolation of NK cells and studies on the mechanism of killing. J Immunol 121: 2509-2517, 1978.

73. Moretta L, Bottino C, Pende D, Vitale M, Mingari MC and Moretta A: Human natural killer cells: molecular mechanisms controlling NK cell activation and tumor cell lysis. Immunol Lett 100: 7-13,2005.

74. Waldhauer I and Steinle A: NK cells and cancer immunosurveillance. Oncogene 27: 5932-5943, 2008.

75. Furue H, Matsuo K, Kumimoto H, et al: Decreased risk of colorectal cancer with the high natural killer cell activity NKG2D genotype in Japanese. Carcinogenesis 29: 316-320, 2008.

76. Szkaradkiewicz A,Karpiński TM,Drews M,Borejsza-WysockiM, Majewski P and Andrzejewska E: Natural killer cell cytotoxicity and immunosuppressive cytokines (IL-10, TGF-beta1) in patients with gastric cancer. J Biomed Biotechnol 2010: 901564, 2010

77. Hammond KJ, Pelikan SB, Crowe NY, et al: NKT cells are phenotypically and functionally diverse. Eur J Immunol 29: 3768-3781, 1999.

78. Jerud ES, Bricard G and Porcelli SA: CD1d-restricted natural killer $\mathrm{t}$ cells: roles in tumor immunosurveillance and tolerance. Transfus Med Hemother 33: 18-36, 2006.

79. Montoya CJ, Pollard D, Martinson J, et al: Characterization of human invariant natural killer T subsets in health and disease using a novel invariant natural killer $\mathrm{T}$ cell-clonotypic monoclonal antibody, 6B11. Immunology 122: 1-14, 2007.

80. Balato A, Unutmaz D and Gaspari AA: Natural killer T cells: an unconventional T-cell subset with diverse effector and regulatory functions. J Invest Dermatol 129: 1628-1642, 2009.

81. Chan AC, Serwecinska L, Cochrane A, Harrison LC, Godfrey DI and Berzins SP: Immune characterization of an individual with an exceptionally high natural killer $T$ cell frequency and her immediate family. Clin Exp Immunol 156: 238-245, 2009.

82. Smyth MJ, Thia KY, Street SE, et al: Differential tumor surveillance by natural killer (NK) and NKT cells. J Exp Med 191: 661-668, 2000.

83. Mercer JC, Ragin MJ and August A: Natural killer T cells: rapid responders controlling immunity and disease. Int J Biochem Cell Biol 37: 1337-1343, 2005

84. Bendelac A, Savage PB and Teyton L: The biology of NKT cells. Annu Rev Immunol 25: 297-336, 2007.

85. Berzofsky JA and Terabe M: The contrasting roles of NKT cells in tumor immunity. Curr Mol Med 9: 667-672, 2009.

86. Swann JB, Uldrich AP, van Dommelen S, et al: Type I natural killer T cells suppress tumors caused by p53 loss in mice. Blood 113: 6382-6385, 2009.

87. O'Shea D, Cawood TJ, O'Farrelly C and Lynch L: Natural killer cells in obesity: impaired function and increased susceptibility to the effects of cigarette smoke. PLoS One 5: e8660, 2010.

88. Lynch LA, O'Connell JM, Kwasnik AK, Cawood TJ, O'Farrelly C and O'Shea DB: Are natural killer cells protecting the metabolically healthy obese patient? Obesity (Silver Spring) 17: 601-605, 2009.

89. Lynch L, O'Shea D, Winter DC, Geoghegan J, Doherty DG and O'Farrelly C: Invariant NKT cells and CD1d(+) cells amass in human omentum and are depleted in patients with cancer and obesity. Eur J Immunol 39: 1893-1901, 2009. 